\title{
Evaluasi Potensi Wisata Alam Pulau Lemukutan Kabupaten Bengkayang, Kalimantan Barat
}

\author{
AGUS RULIYANSYAH ${ }^{1}$
}

1. Program Studi Agroteknologi, Fakultas Pertanian, Universitas Tanjungpura Jalan Prof DR. Hadari Nawawi, Kode Pos 1049, Indonesia

*E-mail: agus.ruliyansyah@faperta.untan.ac.id

\section{ABSTRACT \\ Evaluation of Potential Ecotourism Lemukutan Island Bengkayang District, West Kalimantan}

Lemukutan Island, Bengkayang, West Kalimantan, has the potential of ecotourism that is very nice. The aims of this study was to evaluate the potential contained in the island tourist Lemukutan to be the basis of sustainable ecotourism management. Some of the potential in the form of beaches, coral reefs, rock promontory, smallholder and seafood. Activities supporting facilities like water supply, transportation and lodging need to be equipped and upgraded. Tourism development must consider biophysical nature so that ecotourism Lemukutan Island can be sustainable.

Keywords: Bengkayang District, ecotourism, Lemungkutan island

\section{Pendahuluan}

Wisata adalah suatu pergerakan temporal menuju ke tempat selain dari tempat mereka tinggal dan bekerja, selama mereka tinggal di tujuannya tersebut, mereka melakukan kegiatan dan diciptakan fasilitas untuk mengakomodasi kebutuhan mereka (Gunn, 1994). Kampung wisata adalah pariwisata yang menawarkan sisi yang menarik dari kehidupan masyarakat kampung dan merupakan suatu bentuk wisata yang menjaga kelestarian alam (natural area), memberi manfaat secara ekonomi dan mempertahankan keutuhan budaya bagi masyarakat setempat.

Undang - Undang Nomor 10 Tahun 2009 tentang Kepariwisataan menjelaskan bahwa pembangunan kepariwisataan diperlukan untuk mendorong pemerataan kesempatan berusaha dan memperoleh manfaat serta mampu menghadapi tantangan perubahan kehidupan lokal, nasional, dan global.

Wakil Menteri Pariwisata dan Ekonomi Kreatif, Sapta Nirwandar dalam harian Tempo menyatakan pertumbuhan industri pariwisata di Indonesia tahun 2014 mencapai 9,39 persen lebih tinggi dari tahun sebelumnya. Sektor pariwisata menyumbangkan produk domestik bruto mencapai Rp 347 triliun. Bila dibandingkan, angka itu mencapai 23 persen dari dengan total pendapatan negara yang tercantum di Anggaran Pendapatan dan 
Belanja Negara Perubahan 2013, yakni Rp 1.502 triliun, Sektor pariwisata juga menempati urutan keempat sebagai penyumbang devisa negara tahun 2013 (www.tempo.co.id)

Peringkat daya saing pariwisata di ASEAN yang dilansir oleh World Economic Forum (2013), posisi Indonesia terus merangkak naik setiap tahunnya. Kini, peringkat daya saing Indonesia berada di urutan ke 70. Pada 2012 ada diurutan 74. Peringkat ini di atas peringkat Brunei (72), Vietnam (80), Filipina (82), serta Kamboja (106) (www.tempo.co.id).

Jumlah wisatawan mancanegara (wisman) yang datang ke Kalimantan Barat masih berfluktuatif, karena tergantung event budaya yang dilaksanakan. Pada Desember 2013 jumlah wisman mencapai 3.639 orang atau naik 23,15 persen dibandingkan jumlah wisman November 2013 sebanyak 2.955 orang. Sedangkan Januari 2014 mencapai 2.264 orang, mengalami penurunan sebesar 37,79 persen dibanding bulan Desember 2013 (http://kalbar.bps.go.id).

Pulau Lemukutan yang terletak di Kabupaten Bengkayang Provinsi Kalimantan Barat, memiliki potensi wisata alam yang sangat bagus. Dengan hamparan pasir putih di pantai dan trumbu karang yang masih terjaga, menjadikan pulau tersebut sebagai tujuan wisata air yang sudah cukup dikenal di tingkat lokal (Kalimantan Barat). Jika ditelusuri di media sosial dan internet, banyak tulisan per orangan yang mengungkapkan keindahan panorama alamnya tersebut. Agar industri wisata di Pulau Lemukutan dapat dikelola secara baik maka perlu dilakukan inventarisasi potensi-potensi wisata yang ada serta mencari beberapa kekurangan yang harus diatasi, agar Pulau lemukutan sebagai daerah tujuan wisata bisa sustainable.

Tujuan dari penelitian ini adalah untuk mengevaluasi potensi-potensi wisata yang terdapat di Pulau Lemukutan untuk menjadi dasar pengelolaan wisata secara berkelanjutan. Untuk itu perlu dilakukan penelitian Evaluasi Pontensi Wisata Alam Pulau Lemukutan, sebagai dasar dalam pengelolaan wisata yang berkelanjutan, dapat memberi nilai ekonomi lebih kepada masyarakat setempat dan menjaga alam tetap asri dan alami.

\section{Metode}

Penelitian dilaksanakan di Pulau Lemukutan, Kecamatan Sungai Raya Kepulauan Kabupaten Bengkayang. Waktu penelitian selama 5 bulan, mulai bulan Juni hingga Oktober 2015. Metode yang digunakan dengan teknik survey. Pelaksanaan evaluasi dilakukan dengan tahapan: (1) studi literatur yang terkait dengan lingkup penelitian, (2) inventarisasi, dan (3) analisis data menggunakan SWOT.

\section{Hasil dan Pembahasan}

\subsection{Luas, Letak dan Aksesibilitas}

Pulau Lemukutan memiliki luas sekitar 1.236 ha. Pulau Lemukutan adalah pulau terbesar dari gugusan Pulau Kabung, Penata Besar, Penata Kecil dan Pulau Randayan. Pulau Lemukutan dapat dicapai melalui akses jalan laut. Terdapat dua dermaga tempat bersandar motor air tujuan Pulau Lemukutan, dermaga yang pertama terletak di Teluk Suak dan yang kedua adalah Dermaga Samudra Indah. 


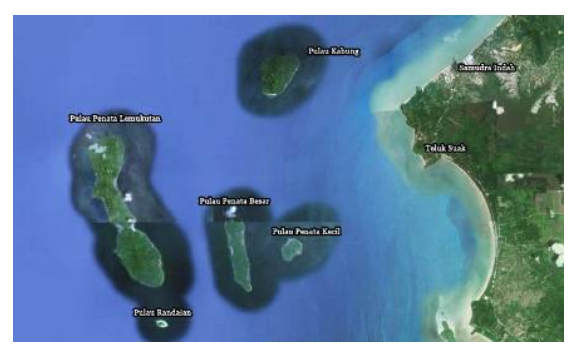

Gambar 1. Letak Pulau Lemukutan dan Kepulauan Sekitarnya

Setiap hari selalu ada motor air yang melayani rute tujuan Pulau Lemukutan. Tarif setiap orang dikenakan sebesar Rp. 10.000,-. Dermaga Samudra Indah akan ramai pada bulan November dan Desember karena pada bulan-bulan tersebut bertiup angin barat yang menyebabkan gelombang laut tinggi sehingga motor air tidak besandar di dermaga Teluk Suak. Jarak antara Pulau Lemukutan dan kedua dermaga tersebut dapat dilihat pada tabel di bawah ini.

Tabel 1. Jarak antara Darmaga Teluak Suak dan Samudra Indah dengan Pulau Lemukutan

\begin{tabular}{cc}
\hline Rute & Jarak (km) \\
\hline Teluk Suak - Pulau Lemukutan & 20 \\
Samudra Indah - Pulau Lemukutan & 18 \\
\hline
\end{tabular}

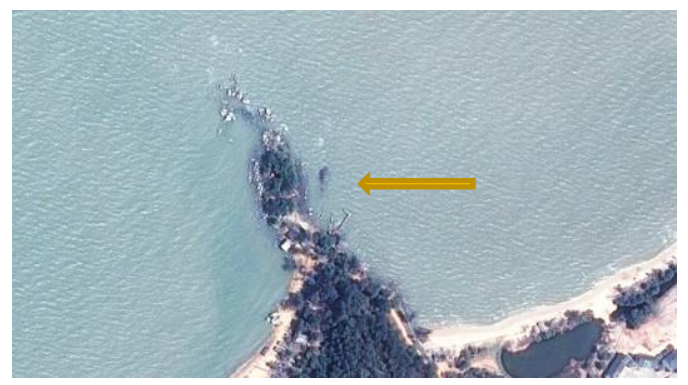

(a)

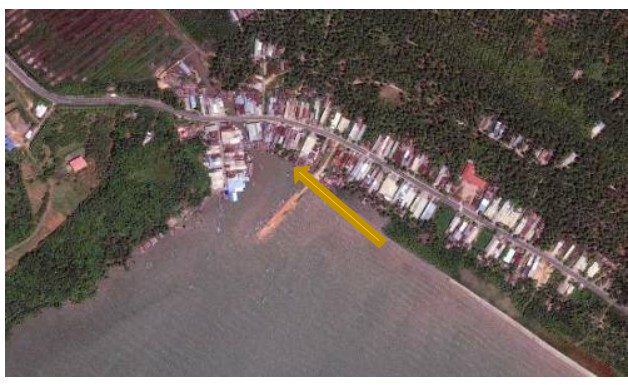

(b)

Gambar 2. Letak Dermaga (a) Samudra Indah dan (b) Teluk Suak

Pulau Lemukutan juga memiliki dua dermaga, yaitu Dermaga Melanau Timur dan Dermaga Telok Cina, akan tetapi dermaga yang menjadi tujuan utama sebagai pintu masuk adalah Dermaga Melanau Timur. Dermaga Telok Cina sering digunakan penduduk lokal yang memang bertempat tinggal di sana. 

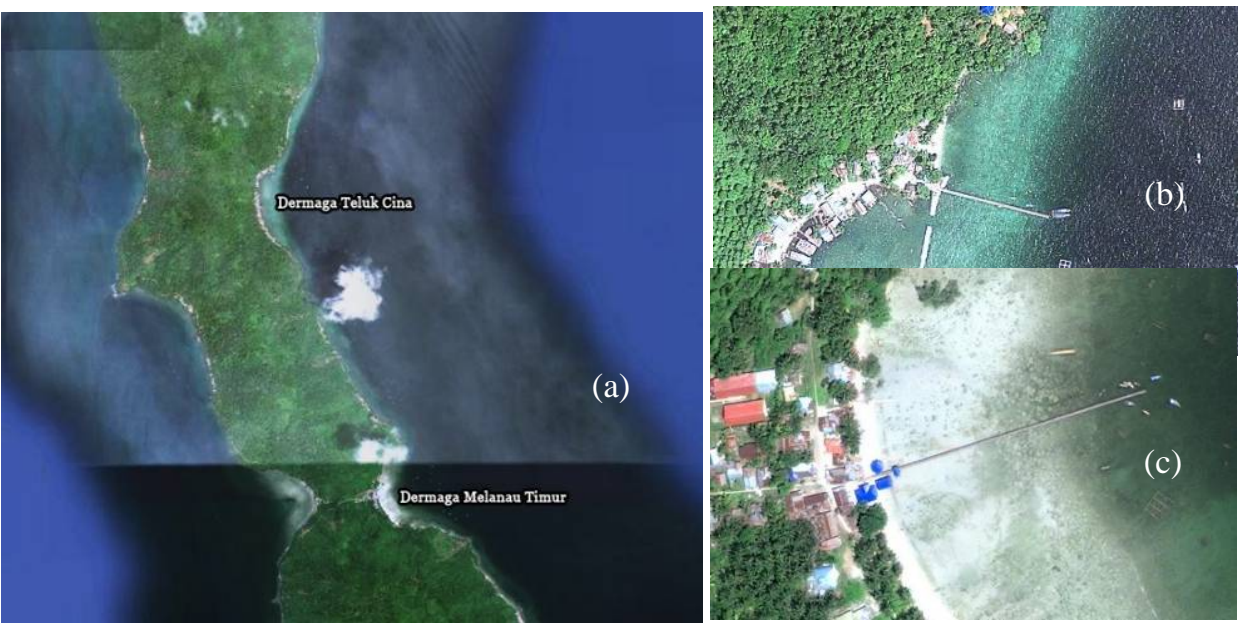

Gambar 3. (a) Darmaga di Pulau Lemukutan, (b) Dermaga Teluk Cina, dan (c) Dermaga Melanau Timur
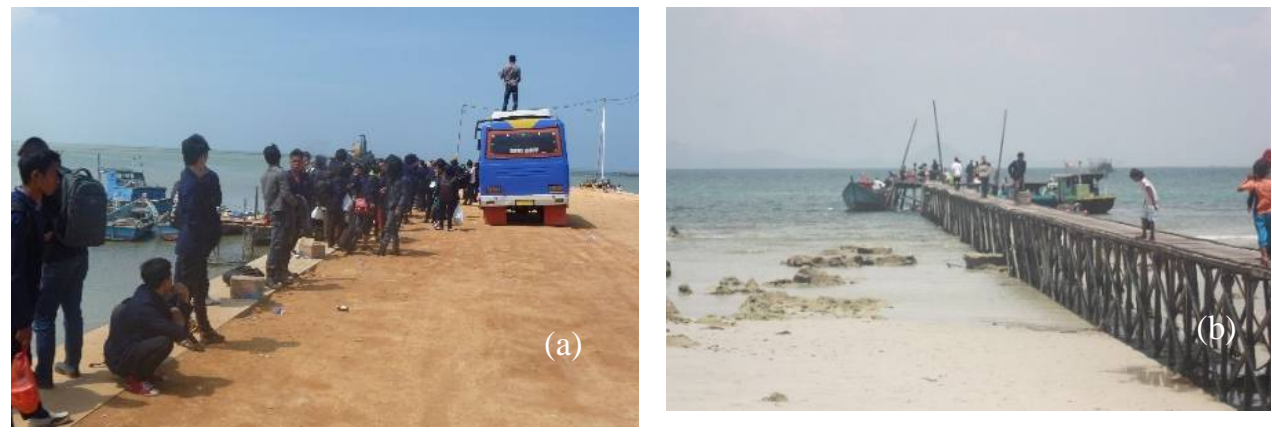

Gambar 4. (a) Kondisi Dermaga Teluk Suak dan (b) Kondisi Dermaga Melanau Timur

\subsection{Topografi dan Fisiografi}

Hasil pengamatan menunjukkan bahwa Pulau Lemukutan memiliki topografi yang bergelombang hingga curam, dimana secara garis besar tapak bagian utara dan selatan mempunyai lereng yang curam terutama pada punggung pulau. Perbedaan titik tertinggi dan terendah sekitar $340 \mathrm{~m}$, dengan titik terendah pada bagian pantai, dan titik tertinggi berada di bagian selatan pulau.

Adanya variasi bentukan permukaan lahan dalam tapak merupakan potensi sekaligus kendala bagi pengembangan tapak. Topografi yang bergelombang di satu sisi membantu mengurangi kemonotonan pada tapak baik secara fisik maupun visual. Di sisi lain, kondisi tersebut dapat membatasi pengembangan ruang dalam tapak sehingga perlu dilakukan penyesuaian kemiringan lahan dengan cut and fill yang memakan biaya besar. Untuk itu, dalam pengembangan tapak perlu dilakukan pemanfaatan karakter permukaan yang bergelombang tersebut semaksimal mungkin. 


\subsection{Hidrologi}

Sumber air tawar tidak banyak ditemukan dalam tapak, hanya berupa sumur gali dan saluran air dari mata air di atas puncak pulau. Berdasarkan kondisi topografi tapak, dapat diperkirakan aliran permukaan yang terjadi secara alami pada tapak yaitu air mengalir dari arah utara tapak menuju tengah atau timur. Masyarakat menggunakan bambu dan pipa pvc untuk mengalirkan air tawar dari sumber mata air ke rumah-rumah.

Kondisi minimnya sumber air tawar pada tapak perlu dipertimbangkan dalam rencana prasarana pada tapak agar nantinya tidak menjadi kendala dalam pengelolaan tapak terutama untuk penyediaan air bersih bagi warga dan pengujung. Arah aliran permukaan perlu diperhitungkan terutama dalam alokasi kegiatan pengunjung dan penempatan struktur penunjang serta prasarana saluran drainase pembuangan. Hal tersebut untuk menghindari timbulnya banjir dan genangan pada tapak, yang dapat menimbulkan kondisi tidak nyaman bagi pengunjung, disamping dapat menimbulkan berbagai sumber penyakit, seperti menjadi menjadi sarang nyamuk, serta sumber penyakit lainnya.

\subsection{Penggunaan Lahan}

Penggunaan lahan di Pulau Lemukutan sebagian besar digunakan sebagai kebun masyarakat, sehingga didominasi oleh vegetasi tanaman kebun terutama tanaman tahunan. Jenis tegakan tanaman yang sering dijumpai antara lain: kelapa (Cocos nucifera), cengkeh (Syzigium aromaticum) dan pala (Myristica fragrans). Jenis pohon tertentu, yaitu cengkeh, pada beberapa titik ditemukan ada yang sudah berumur tua. Sementara itu pada strata penutup tanah dan semak di tapak, selain berupa rumput, juga tumbuh paku-pakuan, tanaman liar berkhasiat obat dan berbunga menarik.
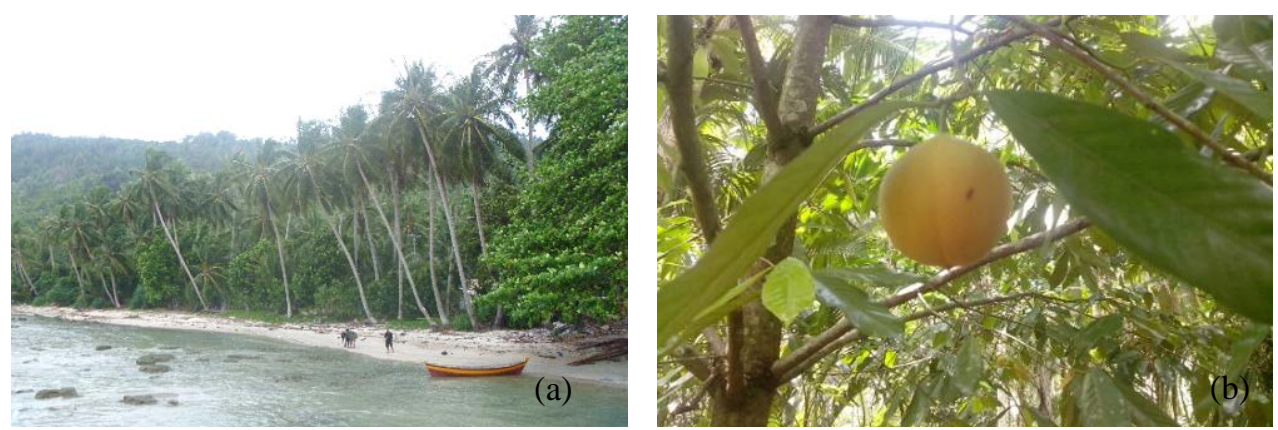

Gambar 5. (a) Barisan Tanaman Kelapa pada Pinggir Pantai dan

(b) Tanaman Pala yang Dibudidayakan Masyarakat

Adanya tegakan pohon buah-buahan dalam tapak, terutama pohon-pohon tua, merupakan potensi, dimana dalam pengembangan tapak perlu dipertahankan. Hal tersebut disebabkan karena pertama, keberadaan pepohonan tersebut menjadi nilai historis tapak. Kedua, penanaman pohon dari usia bibit hingga dewasa membutuhkan waktu bertahun-tahun, sehingga dengan mempertahankan pepohonan yang kondisi arsitektural dan fisiologinya masih baik akan membantu segera terbentuknya ruang hijau pada tapak. Untuk itu maka pengembangan akan dilakukan dengan menyesuaikan pada 
potensi vegetasi yang memiliki nilai historis tersebut diatas dengan penyelarasanpenyelarasan yang optimal. Penggunaan lahan lainnya adalah kawasan pemukiman, kawasan pendidikan dan kantor instansi. Penggunaan lahan untuk pengembangan wisata perlu dipertimbangkan mengingat hal tersebut melibatkan masyarakat setempat.

\subsection{Potensi Wisata}

Pulau Lemukutan memiliki pemandangan alam yang indah. Pemandangan pantai, laut dan punggung pulau yang berbukit memiliki potensi yang dapat dikembangkan dan dikemas dalam paket-paket wisata ecotourism. Adapun tempat yang memiliki keindahan dan atraksi yang menarik adalah:

\subsubsection{Pantai}

Pulau Lemukutan memiliki pantai yang indah. Pasirnya yang putih dan bersih serta pasang surut air laut memberikan suasana asri. Berikut gambar beberapa pantai yang ada di Pulau Lemukutan
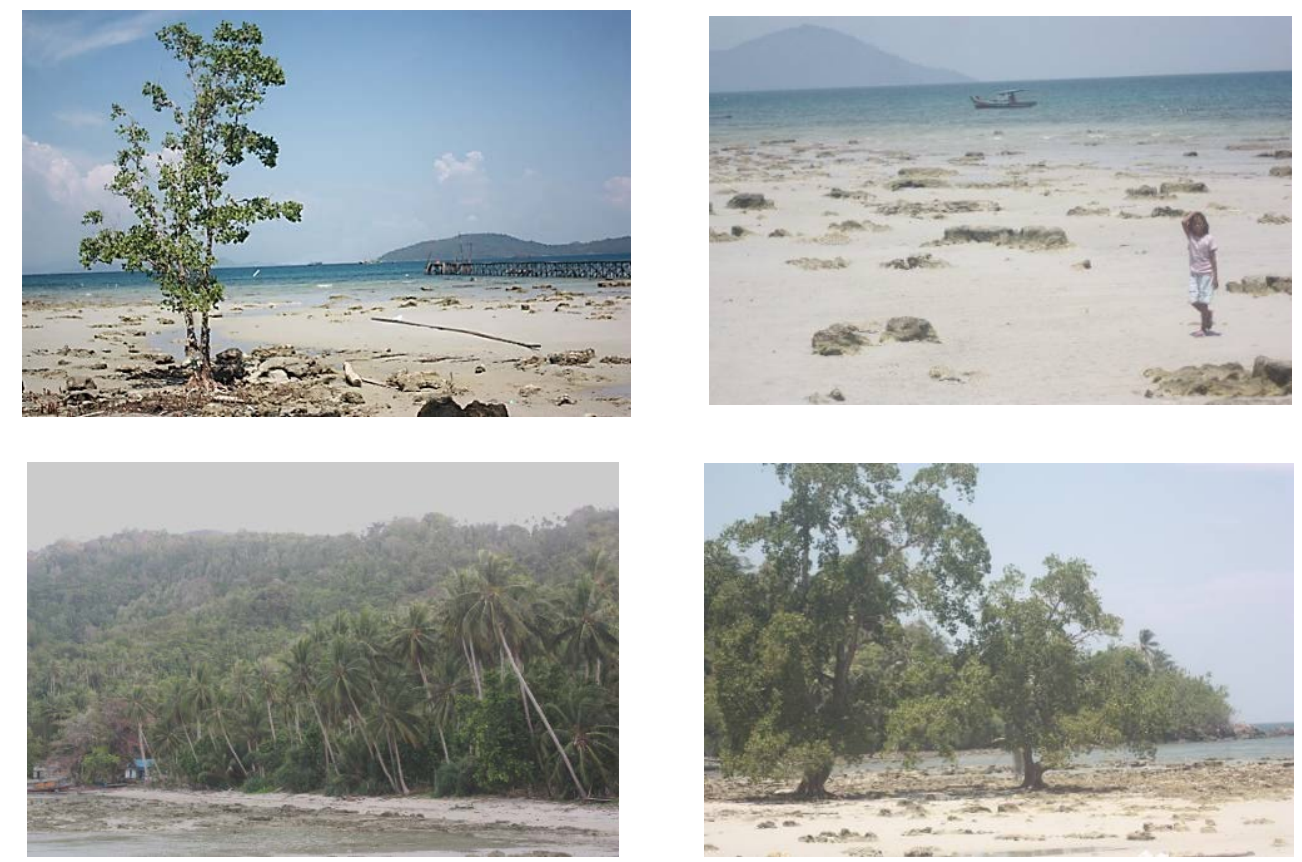

Gambar 6. Kondisi Pantai Pulau Lemukutan

\subsubsection{Terumbu Karang}

Terumbu karang di pesisir pantai masih terawat. Ikan-ikan kecil dan warna-warni dapat dijumpai di sekitar terumbu karang tersebut. Beberapa terumbu karang akan muncul dipermukan pada saat air laut sedang surut. 

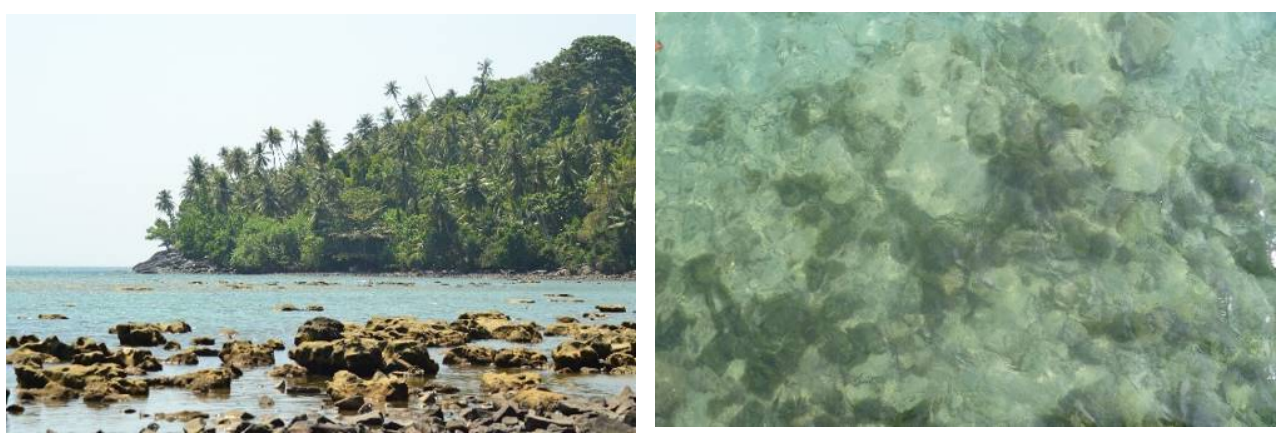

Gambar 7. Kondisi Terumbu Karang Pulau Lemukutan

\subsubsection{Sunset}

Sisi sebelah barat Pulau Lemukutan pada saat petang dapat menyaksikan proses tenggelamnya matahari. Langit merah keemasan sangat indah menyertai masuknya matahari dibatas pandang laut yang membentang.
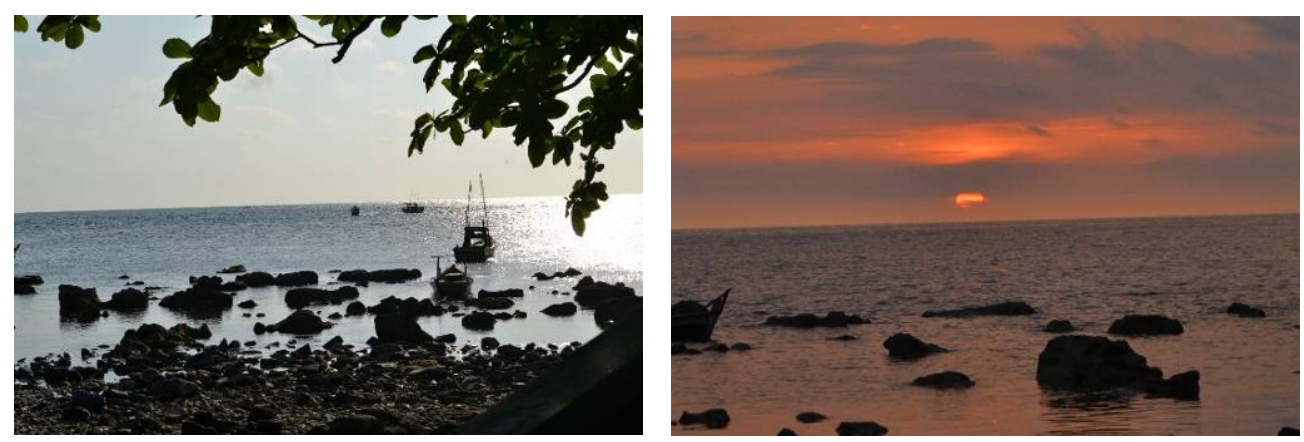

Gambar 8. Pemandangan Saat Matahari akan Tenggelam

\subsubsection{Tanjung Batu}

Tanjung-tanjung batu dapat ditemui pada beberapa tempat di Pulau Lemukutan. Tanjung ini menjorok ke laut dengan bebatuan yang besar-besar. Lokasi tersebut sangat indah untuk dinikmati.
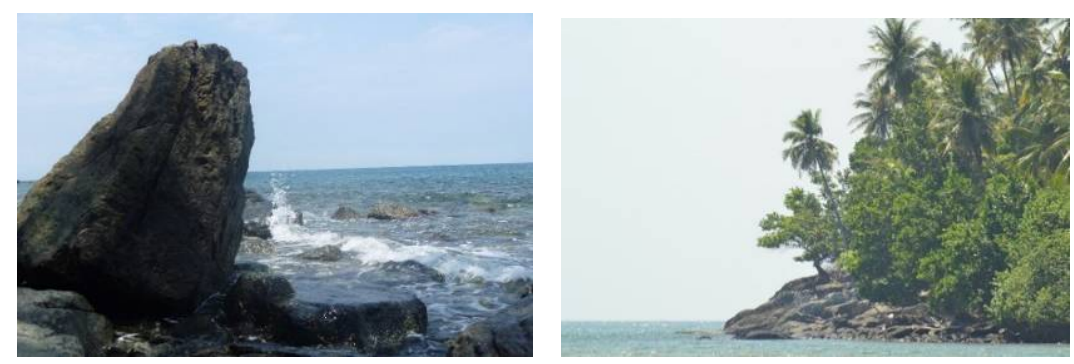


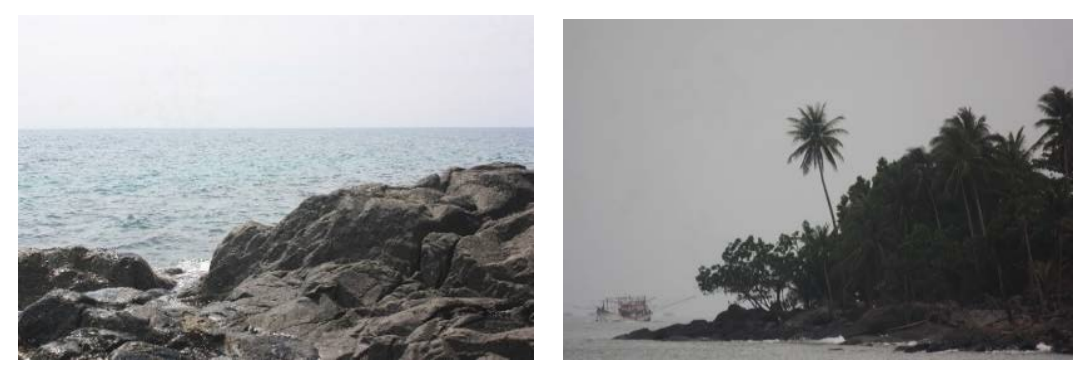

Gambar 9. Tanjung Batu dengan Hamparan Bebatuan yang Eksotis

\subsubsection{Perkebunan Masyarakat}

Masyarakat mengusahakan tanaman rempah-rempahan berupa cengkeh dan pala. Komoditi ini merupakan komoditi unggulan dan spesifik lokasi karena tanaman tersebut dapat tumbuh dengan baik di Pulau Lemukutan.
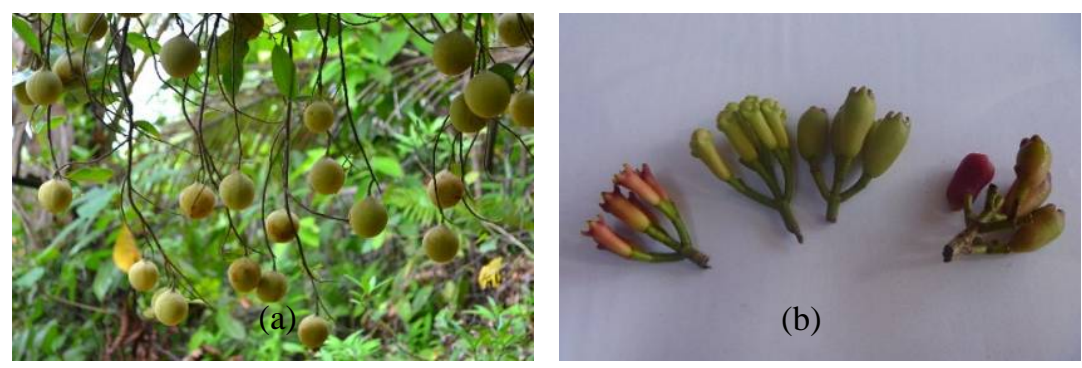

Gambar 10. Komoditi Unggulan (a) Pala, dan (b) Cengkeh

\subsubsection{Ikan dan Hasil Laut}

Melaut adalah mata pencaharian masyarakat selain bertani. Nelayan turun ke laut dan kembali pada siang atau sore hari. Berbagai hasil tangkapan berupa ikan dapat kita beli langsung dalam kondisi segar. Selain ikan, beberapa hewan laut dapat kita temui seperti kerang dan teripang.
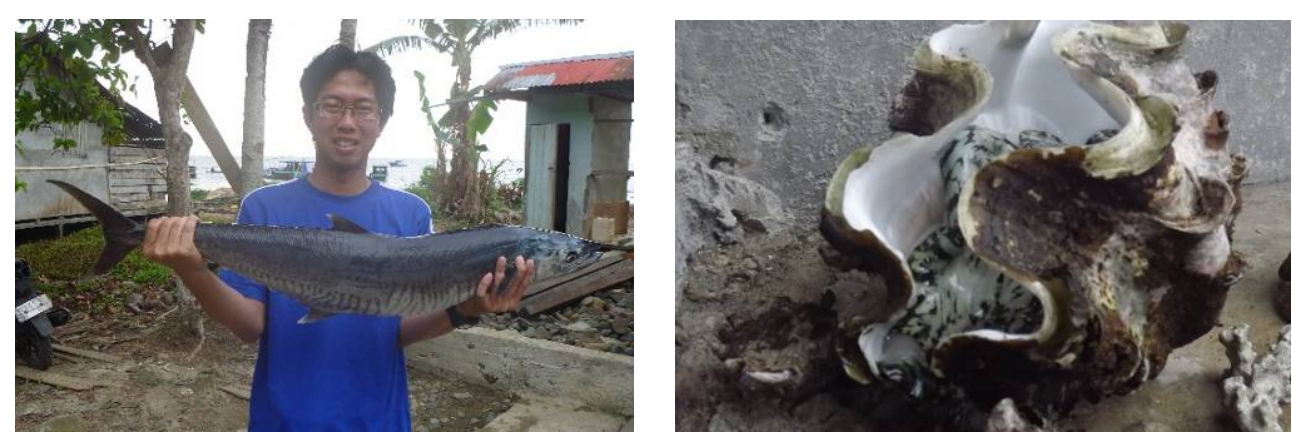

Gambar 11. Hasil Laut di Pulau Lemukutan 


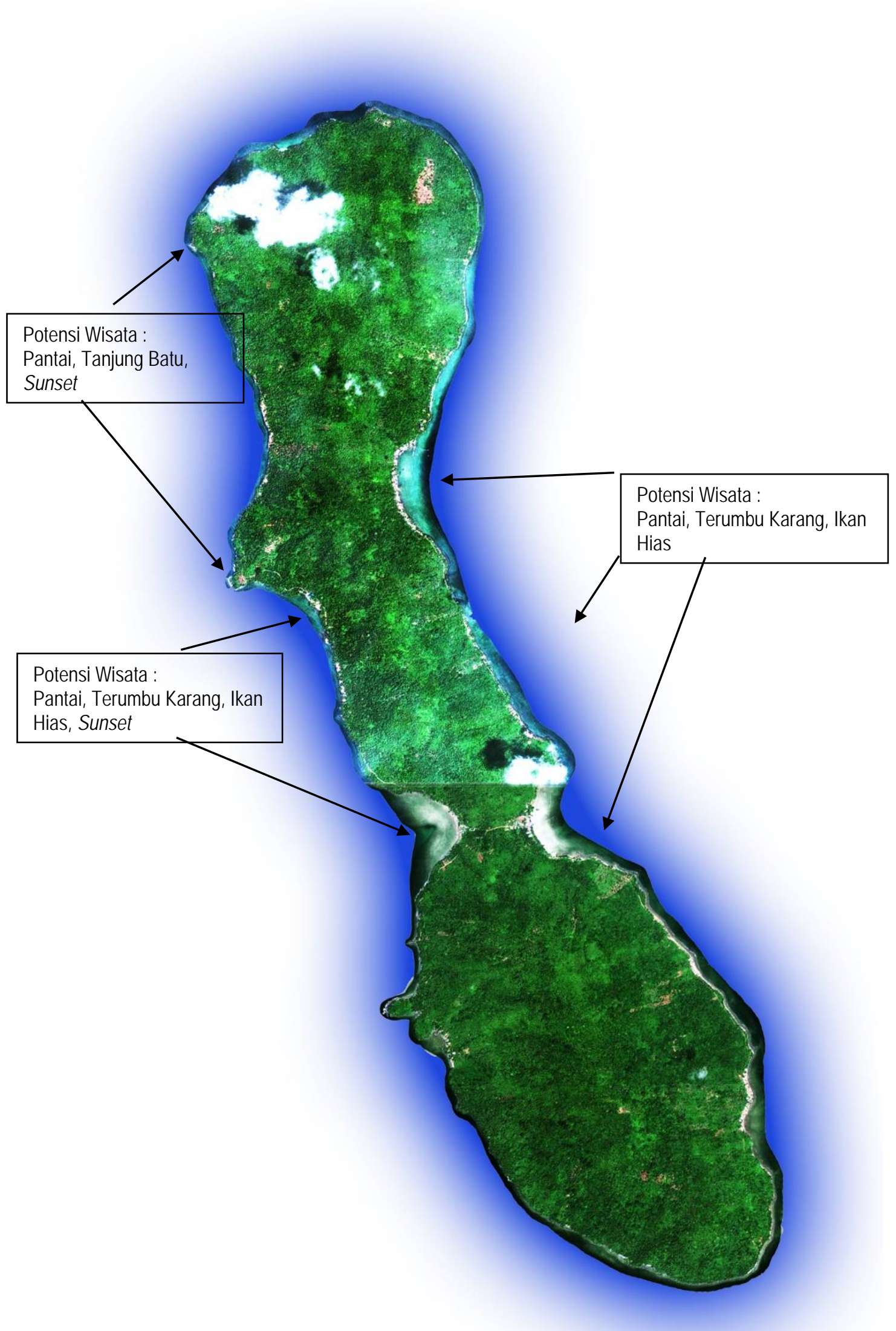

Gambar 12. Potensi Wisata di Pulau Lemukutan 


\subsection{Evaluasi Potensi Wisata Alam Pulau Lemukutan}

Berdasarkan hasil analisis secara deskriptif dan spasial pada Pulau Lemukutan, diperoleh bahwa terdapat beberapa kondisi yang mendukung wisata alam dengan pengembangan ecotourism. Namun demikian, terdapat beberapa hal dan kondisi perlu dibenahi untuk mendapatkan penataan kawasan yang fungsional dan estetik.

Tabel 2. menunjukkan aspek permasalahan pada tapak beserta pemecahannya yang akan diadopsi dalam perencanaan.

Tabel 2. Aspek, Permasalahan dan Pemecahan Masalah pada Tapak.

NO ASPEK Permasalahan Pemecahan Masalah

I. BIO-FISIK

1. Luas, Letak, Aksesibilitas

2. Topografi dan Fisiografi

3. Hidrologi

4. Vegetasi

5. Penggunaan Lahan
Terbatasnya pilihan angkutan/kendaraan menuju lokasi.

Topografi bergelombang mempersulit pembangunan struktur bangunan

Minimnya sumber air tawar

Tidak semua pepohonan dapat dipertahankan karena perubahan peruntukan ruang sesuai rencana tapak nantinya

Adanya penggunaan lahan eksisting yang tidak sesuai dengan konsep perencanaan.

\section{PENGGUNA TAPAK}

1. Masyarakat Sekitar Tapak

2 Penginapan atau Home Stay
Adanya kegiatan masyarakat sekitar tapak yang tidak sesuai dengan perencanaan.

Jumlah dan mutu penginapan yang belum memenuhi standar
Perlu disiapkan beberapa jenis angkutan untuk membawa wiasatawan ke lokasi, baik berupa motor air, speed boat atau ferry.

Bangunan yang akan didirikan disesuaikan dengan bangunan lokal di daerah sekitar tapak dan dibangun mengikuti topografi tapak.

Perlu dibuatkan bak-bak penampung dengan kapisata yang besar untuk menjaga ketersediaan air tawar.

Pohon-pohon lokal yang ada terutama yang mendukung konsep perencanaan pada tapak akan dipertahankan, sedangkan yang tidak akan dihilangkan.

Penggunaan dalam tapak perlu diakomodir atau dialokasikan keluar tapak

Kegiatannya dalam tapak diakomodir atau dialokasikan keluar tapak

Meningkatkan jumlah dan kualitas rumah penginapan. Minimal fasilitas standar standar dipenuhi 
Pemecahan masalah yang ada dibuat berdasarkan perencanaan yang akan dikembangkan. Pengembangan dan penataan tapak sebagai kawasan wisata alam memerlukan perencanaan yang baik dari segi kualitas dan kuantitas sehingga dapat mengakomodasi kebutuhan wisatawan dan penduduk setempat, baik secara esetetika, ekologis, sosial dan ekonomi. Ketersediaan berbagai fasilitas pada tapak sangat diperlukan untuk mendukung kegiatan tersebut.

\section{Simpulan}

1. Pulau Lemukutan memiliki potensi alam yang sangat indah dan cocok untuk pengembangan ekowisata. Beberapa potensi tersebut berupa pantai, terumbu karang, tanjung batu, perkebunan rakyat dan hasil laut.

2. Perlu dilengkapi fasilitas penunjang kegiatan wisata seperti ketersediaan air bersih, alat trasportasi serta penginapan.

3. Pengembangan kawasan wisata harus memperhatikan aspek biofisik agar kawasan wisata alam Pulau Lemukutan dapat lestari

\section{$5 \quad$ Daftar Pustaka}

Hack G. 1988. Physical Planning and Urban Desaign. Di dalam: Catanese, A.J. and J.C. Snyder (eds.). Urban Planning. McGraw-Hill, Inc.

Hakim R. 1991. Unsur Perancangan dalam Arsitektur Lanskap. Jakarta: Bumi Aksara.

Harris CW dan Dines NT. 1988. Time Saver Standar for Landscape Architecture: Design and Construction Data. New York: Mc Graw-Hill Book Co.

Hill, WF.1995. Landscape Handbook for The Tropics. New York: Packard Publishing.

www.kalbar.bps.go.id/index.php?option=com_content\&view=article\&id=621:perkembangan -pariwisata-dan-transportasi-kalimantan-barat-januari-2014\&catid=3:berita-resmistatistik\&ltemid=321. (Akses 17 Juni 2015)

www.kalbar.bps.go.id/index.php?option=com_content\&view=article\&id=610:perkembangan -pariwisata-dan-transportasi-kalimantan-barat-desember-2013\&catid=3:beritaresmi-statistik\&Itemid=321. (Akses 17 Juni 2015)

www.tempo.co/read/news/2014/03/06/202559869/Pariwisata-Indonesia-Lampaui-

Pertumbuhan-Ekonomi. (Akses 17 Juni 2015) 